\title{
Flexible ureteroscopy: technique, tips and tricks
}

\author{
Steeve Doizi ${ }^{1,2,3} \cdot$ Olivier Traxer $^{1,2,3}$
}

\begin{abstract}
During the last decades, the surgical management of kidney stones benefited of many technological advances and one of them is the development of flexible ureteroscopy (fURS). This tool, ancillary equipment such as graspers and baskets, and lithotripsy technique with Holmium:YAG laser underwent many improvements leading to a widening of its indications with diagnostic and therapeutic management of upper urinary tract pathologies such as urolithiasis and urothelial tumors. The objective of this review is to describe the surgical technique for fURS as well as tips and tricks for the treatment of renal stones.
\end{abstract}

Keywords Ureterocopy $\cdot$ Ureterorenoscopy $\cdot$ Technique $\cdot$ Kidney stones $\cdot$ Urolithiasis

\section{Introduction}

During the last decades, the surgical management of kidney stones benefited of many technological advances and one of them is the development of flexible ureteroscopy (fURS).

This tool, ancillary equipment such as graspers and baskets, and lithotripsy technique with Holmium:YAG laser underwent many improvements leading to a widening of its indications with diagnostic and therapeutic management of upper urinary tract pathologies such as urolithiasis and urothelial tumors.

Firstly described in 1964 by Marshall, the uretroscope was only passively deflectable and did not include working channel. Although the first successful procedure in humans with a ureteroscope integrating active deflection has been reported by Takayasu, it was not until 1987 that Demetrius Bagley introduced flexible ureteroscopy as we know it today

Olivier Traxer

olivier.traxer@aphp.fr

Steeve Doizi

steeve.doizi@aphp.fr

1 Department of Urology, Tenon Hospital, AssistancePublique Hôpitaux de Paris, 4 rue de la Chine, 75020 Paris, France

2 Pierre et Marie Curie University, Paris, France

3 Groupe de Recherche Clinique sur la Lithiase Urinaire, Tenon Hospital, Assistance Publique-Hôpitaux de Paris, Paris, France
[1-5]. At this time, the fURS suffered from many weaknesses: low angle of deflection, poor resolution, difficult ureteral insertion and lack of irrigation [3]. But fURS benefited of many improvements between 1980 and 1990: fiberoptics for image relay and light transmission, miniaturization of the outer diameter, working channel, and passive and active deflections in both upward and downward directions. After 2000, another major development was introduced: the digital imaging system, improving the image quality substantially. Currently, we can distinguish two types of fURS: fiberoptic and digital fURS. The difference between them is the image relay and light transmission. In fiberoptic fURS, light and image are transmitted in analog format through fiberoptics bundles whereas illumination in digital scopes is made by fiberoptics or by a diode (DEL) and image capture charged by a digital sensor located at the tip of the endoscope: either charged coupled device (CCD) or complementary metal oxide semiconductor (CMOS). In both fiberoptic and digital fURS, most manufacturers have models with a 3.6 Fr working channel (for irrigation and use of accessory instruments) and at least one $270^{\circ}$ active deflection of the tip. The most recent development in fURS was the introduction of single use digital fURS [6, 7].

Due to all these technological advances, fURS has gained in popularity and has become a treatment of choice for kidney stones.

The objective of this review is to describe the surgical technique for fURS as well as tips and tricks for the treatment of renal stones. 


\section{Indications}

The different options of treatment offered to patients with kidney stones are:

- Extracorporeal shockwave lithotripsy (ESWL),

- Flexible ureteroscopy (fURS),

- Percutaneous Nephrolithotomy (PCNL): standard and miniaturized PCNL (mini-PCNL, ultramini-PCNL, micro-PCNL),

- Open surgical and laparoscopic removal.

In case of cystine or uric acid stones, ESWL is not an option because cystine stones are often poorly radioopaque and resistant to ESWL fragmentation, and pure uric acid stones are radiolucent.

According to the last EAU guidelines, the indications for active stone removal of renal stones are: symptomatic stones (e.g., pain or hematuria), stones $>15 \mathrm{~mm}$, stones $<15 \mathrm{~mm}$ if observation is not the option of choice, obstruction caused by stones, stone growth, stones in high-risk patients for stone formation, infection, patient preference, comorbidity, social situation of the patient (e.g., profession or travelling), choice of treatment [8]. AUA Guidelines support stone treatment for asymptomatic stones in cases of stone growth, associated infection, and specific situations such as vocational reasons. Otherwise, surgical treatment is indicated for patients with symptomatic stones and/or obstruction.

Once the indication for stone removal is taken, the choice of the treatment modality depends on several stone characteristics such as: size, location, composition (if available), collecting system anatomy; and other factors such as: complication rate, patient comorbidities, patient preference, available technical equipment, and economic aspects.

Both AUA and EAU provide recommendations for the selection of procedure for active removal of kidney stones [8-10].

\section{AUA guidelines $[9,10]$}

The latest recommendations of the AUA on surgical treatment of kidney stones were published in 2016.

ESWL, fURS, and PCNL are the treatment options for symptomatic patients with $<20 \mathrm{~mm}$ non-lower pole renal stone. ESWL or fURS is recommended as first-line treatment for such stones because their stone-free rates are acceptable and have less morbidity compared to PCNL.

For symptomatic $\leq 10 \mathrm{~mm}$ lower pole kidney stone, ESWL and fURS are the two options that urologists should
Table 1 AUA treatment algorithm for renal calculi $(<20 \mathrm{~mm}$ lower pole renal calculi excluded)

Kidney stone ( $<20 \mathrm{~mm}$ lower pole stone excluded)

$<20 \mathrm{~mm}$

ESWL or fURS

$>20 \mathrm{~mm}$

PCNL

Table 2 AUA treatment algorithm for $<20 \mathrm{~mm}$ lower pole renal calculi

Lower pole renal stone $<20 \mathrm{~mm}$

$\leq 10 \mathrm{~mm}$

ESWL or fURS

$10-20 \mathrm{~mm}$

Endourology (fURS or PCNL)

offer. However, patients with a skin-to-stone distance greater than $9-10 \mathrm{~cm}$ or stone attenuation greater than 900-1000 Hounsfield units have less successful results with ESWL. An endoscopic approach (fURS or PCNL) is recommended for $10-20 \mathrm{~mm}$ lower pole renal stones because they appear to be less affected by stone burden than ESWL.

For stones $>20 \mathrm{~mm}, \mathrm{PCNL}$ is recommended as first-line option because it offers a higher stone-free rate than ESWL or fURS and is less invasive than open surgery or laparoscopic/robotic-assisted procedures. PCNL should also be the first treatment utilized for most patients with staghorn calculi.

fURS should be offered as first-line therapy in most patients who require active stone removal with uncorrected bleeding diatheses or who require continuous anticoagulation/antiplatelet therapy.

The recommendations are summarized in Tables 1 and 2 .

\section{EAU guidelines [8]}

The latest recommendations of the EAU on surgical treatment of kidney stones were published in 2017.

ESWL and fURS are the first-line treatment options for renal stone $<10 \mathrm{~mm}$.

For 10-20 mm non-lower pole renal stone, ESWL, fURS, and PCNL are the treatment options that clinicians should offer. For 10-20 mm lower pole renal stone, PCNL or fURS is recommended in case of unfavorable factors for ESWL because its efficacy is limited. With favorable factors for ESWL, ESWL or an endoscopic approach (fURS or PCNL) should be offered. Unfavorable factors for ESWL are: shockwave-resistant stones (calcium oxalate monohydrate, brushite, or cystine), steep infundibular-pelvic angle, long lower pole calyx $(>10 \mathrm{~mm})$, and narrow infundibulum $(<5 \mathrm{~mm})$.

Kidney stone greater than $20 \mathrm{~mm}$ should be treated by PCNL first-line because it offers a higher stone-free rate than ESWL or fURS. In case PCNL is not an option or contraindicated, renal stone $>20 \mathrm{~mm}$ may be treated 
Table 3 EAU treatment algorithm for renal calculi (10-20 mm lower pole renal calculi excluded)

\begin{tabular}{ll} 
Kidney stone (10-20 mm lower pole renal stone excluded) \\
$<10 \mathrm{~mm}$ & 1. ESWL or fURS \\
& 2. PCNL \\
$10-20 \mathrm{~mm}$ & ESWL or endourol- \\
& ogy (fURS or \\
& PCNL) \\
$>20 \mathrm{~mm}$ & 1. PCNL \\
& $2 . \mathrm{fURS}$ or ESWL \\
\hline
\end{tabular}

Table 4 EAU treatment algorithm for 10-20 mm lower pole renal calculi

\begin{tabular}{lc}
\hline Unfavorable factors for ESWL & Options for treatment \\
\hline $10-20$ mm lower pole renal stone $(>20$ and $<10 \mathrm{~mm}$ : as above) \\
Yes & 1. Endourology (fURS or PCNL) \\
& 2. ESWL \\
No & ESWL or endourology (fURS or \\
& PCNL) \\
\hline
\end{tabular}

with fURS. However, in that case there is a higher risk of staged procedures and placement of a ureteral stent may be needed.

In case of an uncorrected bleeding disorder or continued antithrombotic therapy, fURS, in contrast to ESWL and PCNL, might offer an alternative approach since it is associated with less morbidity.

The recommendations are summarized in Tables 3 and 4 .

\section{Contraindications}

There are no specific contraindications to perform fURS apart from general problems such as general anesthesia or untreated preoperative positive urinalysis.

\section{Technique, tips and tricks}

\section{Patient positioning, anesthesia}

The patient is placed in lithotomy position. Although local, spinal anesthesia and intravenous sedation are feasible options; general anesthesia is suggested because it offers some advantages: renal movement caused by respiration may affect renal navigation and lithotripsy whereas with the mechanical ventilation the use of apnea stops temporarily these issues [11-13]. Furthermore, in case of large stone burden the time frame for spinal anesthesia can be exceeded, requiring a second general anesthesia to complete the procedure.
Access to the upper urinary tract and ureteral access sheath placement

The procedure starts with a rigid cystoscopy to look for location and configuration of the ureteral orifices. Then, a guidewire is placed into the renal cavities. Our preference is to use a $0.035^{\prime \prime}$ stiff hydrophilic guidewire. They are other options than hydrophilic guidewire but a key point is that this latter has to be stiff in order to insert easily instruments and/or stents over it. Although the feasibility of performing fURS without a working or safety guidewire and without intraoperative complications has been reported, we suggest the use of a safety guidewire as it is still useful and does not add any morbidity. Moreover, the use of a safety guidewire ensures access to the collecting system and facilitates the insertion of a stent in case of ureteric or collecting system injury such as ureteral perforation or excessive bleeding [14-18]. Alternatively, the procedure may start with a first-look semirigid ureteroscopy, always using a safety guidewire, which has the advantage of passively dilating the whole ureter in order to choose the most appropriate ureteral access sheath (UAS) size [19]. Once the guidewire has been placed with or without performance of semirigid ureteroscopy, the fURS may be passed up to the kidney alongside this safety guidewire or over a second guidewire (inserted using a dual-lumen catheter) under fluoroscopic guidance. The other option is to place a UAS under fluoroscopic control and insert the fURS through the UAS. These different options for endoscope insertion depend on stone burden, upper urinary tract anatomy, and surgeon's preference.

The goals of the UAS are: to facilitate multiple passages for stone fragments removal and most importantly providing irrigation with better fluid outflow, thereby decreasing the intrarenal pressure [2, 20-23]. The choice of the UAS, its size and diameter depends on the patient's anatomy, the endoscope used, and surgeon's preference [24, 25]. Instead of using two guidewires, some new designed UAS use only one guidewire, meaning the working guidewire turns into safety guidewire [26, 27] (Fig. 1). Attention has to be paid to the force applied during UAS placement because ureteral lesions may be the consequence of forced manoeuvers. Furthermore, in case of second session procedure, the presence of stone fragments, which may have migrated into the ureter, has to be removed before any UAS insertion. If any resistance is encountered during UAS placement, this latter should be stopped and the endoscope introduced to explore the ureter. If not possible, it is safer to place a ureteral stent for passive ureteral dilation, making a secondary fURS procedure much easier to perform at a later date. The best position of the UAS is with its tip in the proximal ureter or just below the ureteropelvic junction but not through it since this is the portion of the ureter at greatest risk for avulsion because of the least muscular tissue support. Taking these 

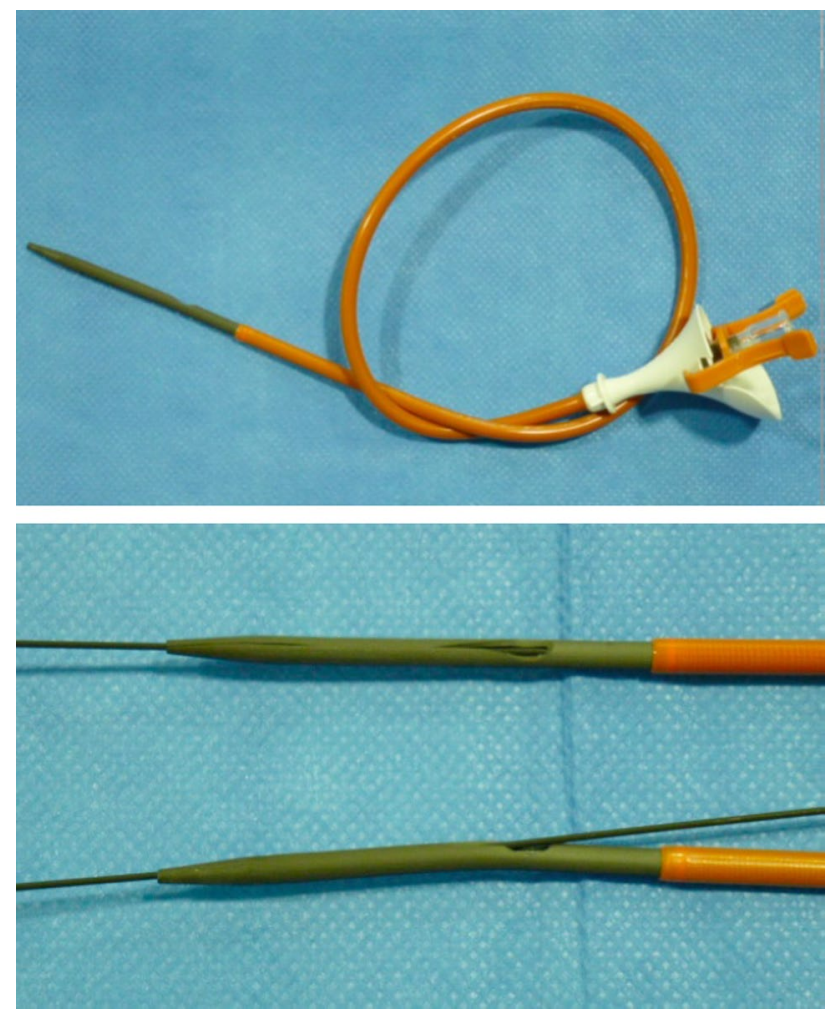

Fig. 1 Ureteral access sheath. The removal of the inner tip automatically converts the working guidewire as a safety guidewire laterally to the sheath

data into consideration, the use of the smaller UAS as possible in accordance with the fURS shaft size fitting is suggested. Depending on the fURS used, we suggest the 10/12Fr UAS as first-line choice as it is the best compromise in terms of intrarenal pressure and irrigation [25].

Once the fURS placed into the kidney, the collecting system is explored starting with the upper calices followed by the middle and lower calices. In the right kidney, the calyces are seen on the left of the endoscope screen. Thus, supination is the essential movement to explore the right renal cavities for urologist with right dominant hand. Conversely, the left renal calyces are seen on the right of the endoscope screen, meaning that pronation is essential when exploring left kidney (Fig. 2).

\section{Lithotripsy and fragment extraction}

Laser lithotripsy, using holmium:yttrium-aluminum-garnet (Ho:YAG) laser and laser fiber, has become the standard for stone lithotripsy during fURS procedure as it proved its efficacy and safety [28]. It delivers a pulsatile energy and operates at a wavelength of $2100 \mathrm{~nm}$ which is the infrared spectrum and is invisible to the human eye. The holmium laser is effective for any composition of stones. Stones are

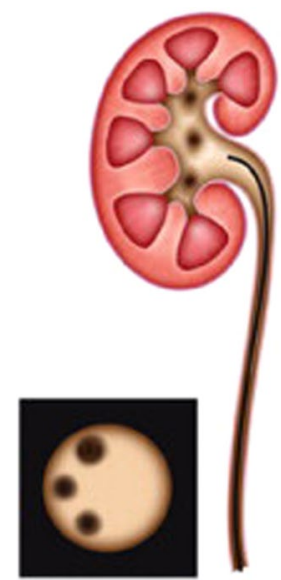

A

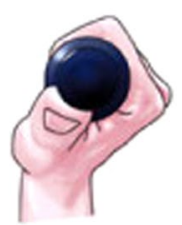

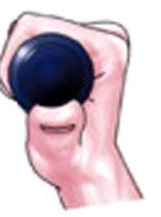

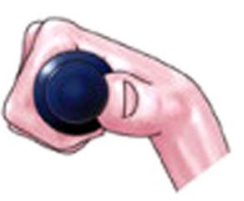

Fig. 2 Dominant-hand pronation and supination to change the direction of the distal tip of the scope. Supination is essential when the scope is in the right renal cavities and pronation is essential when the fURS is in the left renal cavities

ablated via a photothermal effect whereby longer laser pulses (100-1000 $\mu \mathrm{s})$ induce a temperature rise inside the stone. Laser radiation is absorbed by residual water in the stone, creating a vapour pressure that breaks the stone [29-31].

Although most of the manufacturers recommend to wear proper eye protection to avoid any corneal or retinal damage in case of unintentional laser exposure, unintentional Ho:YAG laser emission in air over distances of more than $5 \mathrm{~cm}$ may not be harmful, even if high pulse energies such as $2 \mathrm{~J}$ are used and for accidental emission periods of up to $3 \mathrm{~s}$. Only corneal lesions may occur in the absence of eye protection and only when laser is set to high energy ( $2 \mathrm{~J}$ ) and activated from a short distance $(0-5 \mathrm{~cm})$. Thus, it will be more beneficial to wear lead-lined glasses as eye lens is highly radiosensitive and prolonged radiation exposure increases the risk of developing cataracts. Furthermore, these lead-lined glasses are as protective as the laser safety glasses to prevent any eye damage [32].

In case of use of reusable laser fiber, most of the manufacturers recommend to prepare the laser fiber tip before initiating laser lithotripsy by stripping several millimeters from the terminal portion of the polymer coating, preventing any possible performance degradation from previous laser emission. However it has been shown that stripping the laser fiber tip reduces lithotripsy performance compared to 

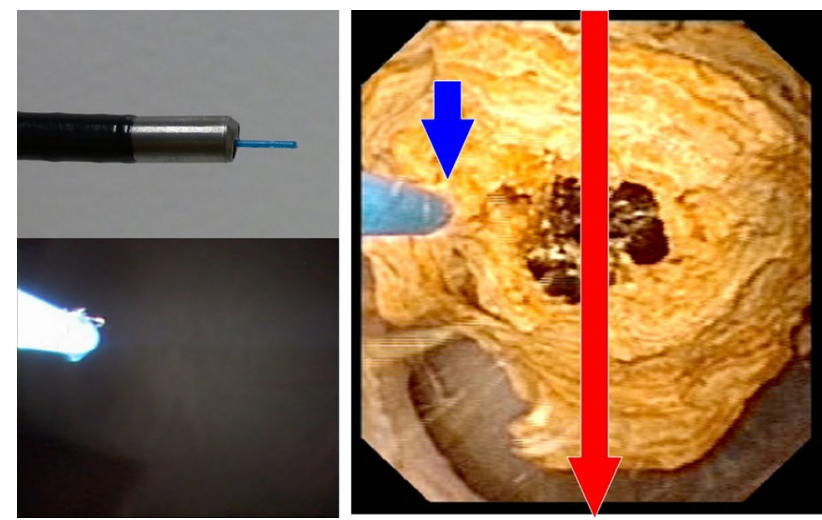

Fig. 3 Laser fiber at one-quarter of the screen in a digital fURS

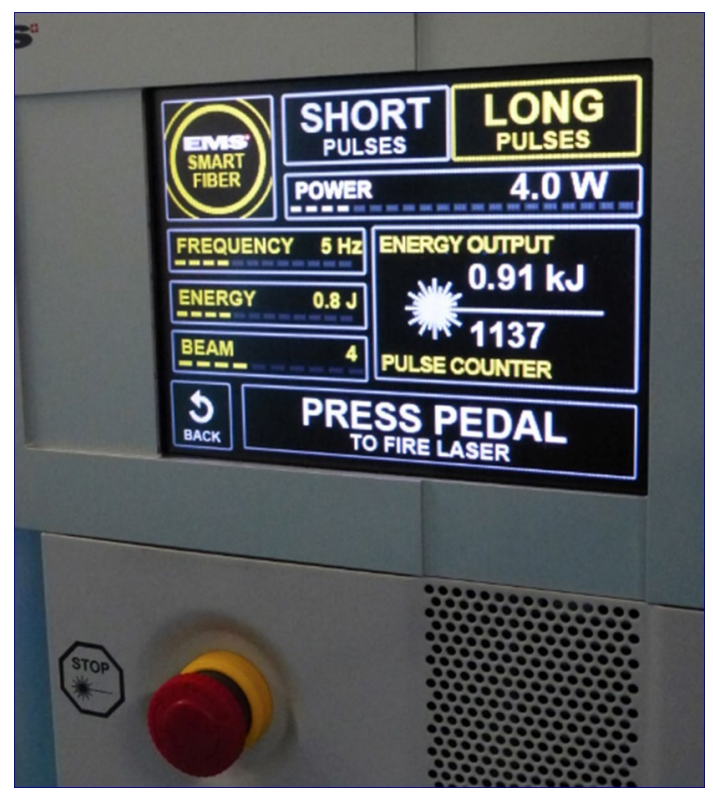

Fig. 4 Laser parameters

coated laser fibers, resulting in a lower ablation volume and higher fiber tip degradation. Moreover, using metal scissors to cleave coated laser fibers does not significantly influence fiber performance compared to ceramic scissors [33, 34].

Once the laser fiber is inserted into the working channel, it is recommended to place the laser fiber tip until reaching one-quarter of the endoscope screen to avoid any fURS tip damage caused by the cavitation bubble created by laser activation (Fig. 3) [35].

The majority of laser lithotripters allow the urologist to control two parameters: the pulse energy and pulse frequency (Fig. 4). The total power output results from the product of these two parameters: total power $(W)=$ pulse energy $(J) \times$ pulse frequency $(\mathrm{Hz})$. By adjusting these parameters, the urologist decides the energy intensity that is delivered at the tip of the laser fiber to ablate the stone. With the release of a new generation of laser lithotripters, a third parameter can be set: the pulse duration. The laser machine allows choosing between short-pulse and longpulse modes (Fig. 3). The difference between these two modes is that for a same amount of energy, its distribution is over a short $(180-330 \mu \mathrm{s})$ or a longer period of time $(650-1215 \mu \mathrm{s})$ [36]. At the same power levels, high frequency-low pulse energy is less efficient than low frequency-high pulse energy lithotripsy. Stone ablation volume directly correlates with pulse energy, whereas frequency, especially high frequency, and total power setting play more minor roles [37]. An in vitro study showed that the shortpulse mode is 25.0 and $9.9 \%$ more ablative than the longpulse mode when associated with low frequency-high pulse energy and high frequency-low pulse energy, respectively [36-38]. Low pulse energy, like high frequency-low pulse energy settings, produces smaller stone fragments (also called "dusting effect") than high-pulse energy, such as low frequency-high pulse energy settings [39-41]. Thus, two options for stone laser lithotripsy are described: "dusting" where the laser lithotripsy reduces the stone to fine dust and to small fragments $2 \mathrm{~mm}$ or less in diameter which are supposed to pass spontaneously avoiding the use of basket, or stone fragmentation producing stone pieces which have subsequently to be removed individually with a basket [39-42] (Fig. 5). Dusting lithotripsy requires to work over the stone's surface and avoid being always in contact at the same place by "panting" with the laser fiber [42]. If fragmentation is performed and a 10/12-Fr UAS used for example, the stones have to be reduced to $3 \mathrm{~mm}$ fragments, which is the maximum stone size that can be removed through this sheath. The removal of such fragments is time consuming and may require a specific laser lithotripsy technique called "popcorn effect" to reduce the stone burden, thereby avoiding numerous entries/reentries with basket [37, 43, 44]. Each method has advantages and disadvantages, but surgeon's preference, stone size, composition, location and intrarenal anatomy determine which ablative technique is the most appropriate. Furthermore, the two techniques can be combined starting with dusting and finishing with fragmentation to get stone pieces for stone analysis. For large stones, the fragmentation alone will produce a multitude of small fragments whose removal may be time consuming. Conversely, complete dusting of such stones may also increase operative time. Thus, both techniques may be used for large stones as well as the "popcorn effect" when significant stone pieces are remaining at the end of the procedure to avoid basketing of all the fragments.

The different laser settings for stone lithotripsy are:

- Fragmentation: high energy (1-2 J), low frequency $(3-5 \mathrm{~Hz})$ and if needed short pulse duration. 

ing effect, $\mathbf{b}$ fragmentation
Fig. 5 Laser lithotripsy. a Dust-
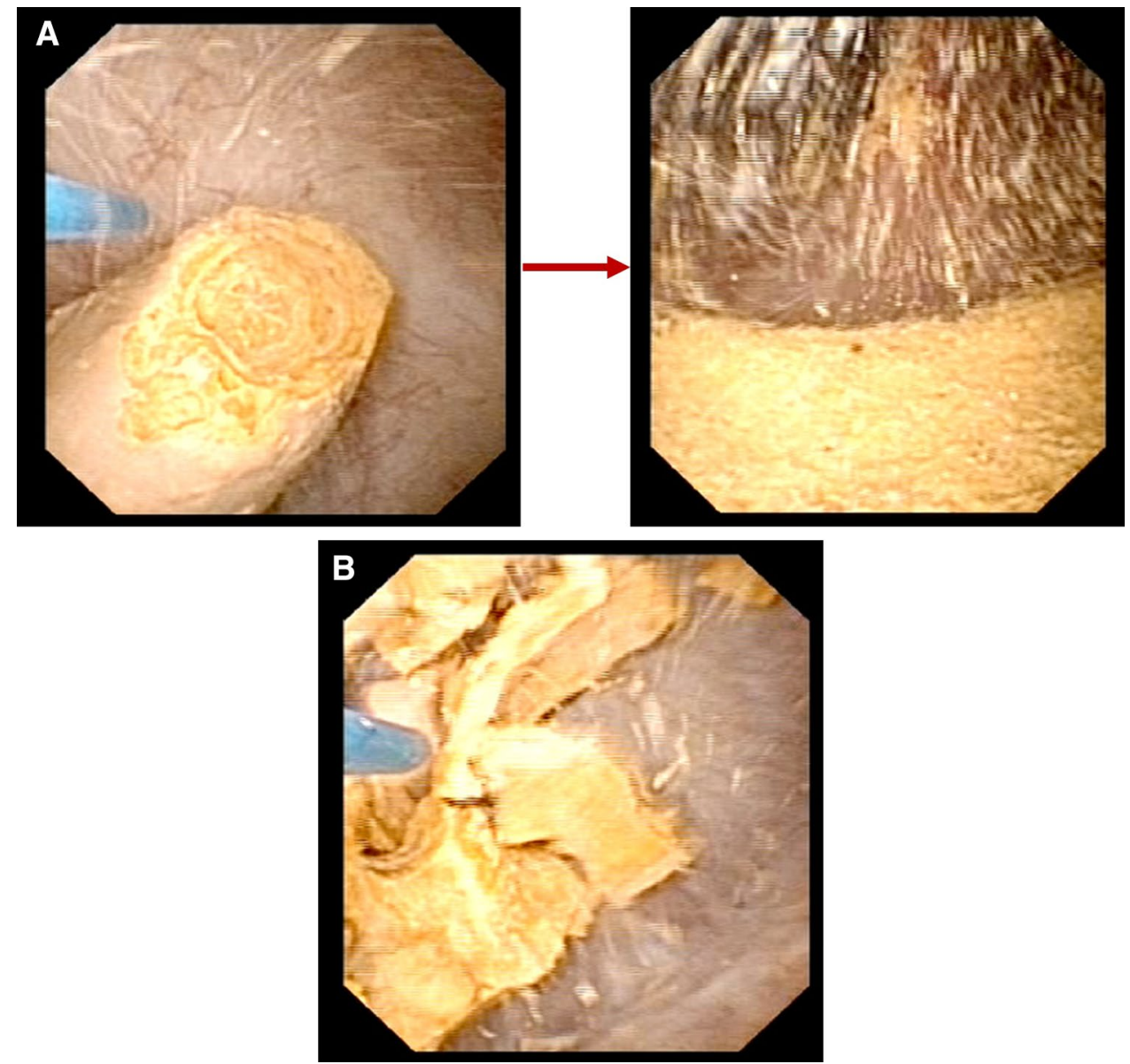

- Dusting: low energy (0.2-0.5 J), high frequency (10$20 \mathrm{~Hz})$ and if needed long pulse duration.

- "Popcorn effect": high energy (1 J), high frequency (10$20 \mathrm{~Hz}$ ) and if needed long pulse duration.
Another parameter which may facilitate laser lithotripsy is the influence of the working channel position. Most of the fURS have a 3 or 9 o' clock working channel position. When performing laser lithotripsy in a right kidney, the calyces are seen on the left of the endoscope screen and the stones are located on the right of the screen because of the gravity.
Fig. 6 Working channel position. Left: 9 o'clock working channel, right: 3 o'clock working channel
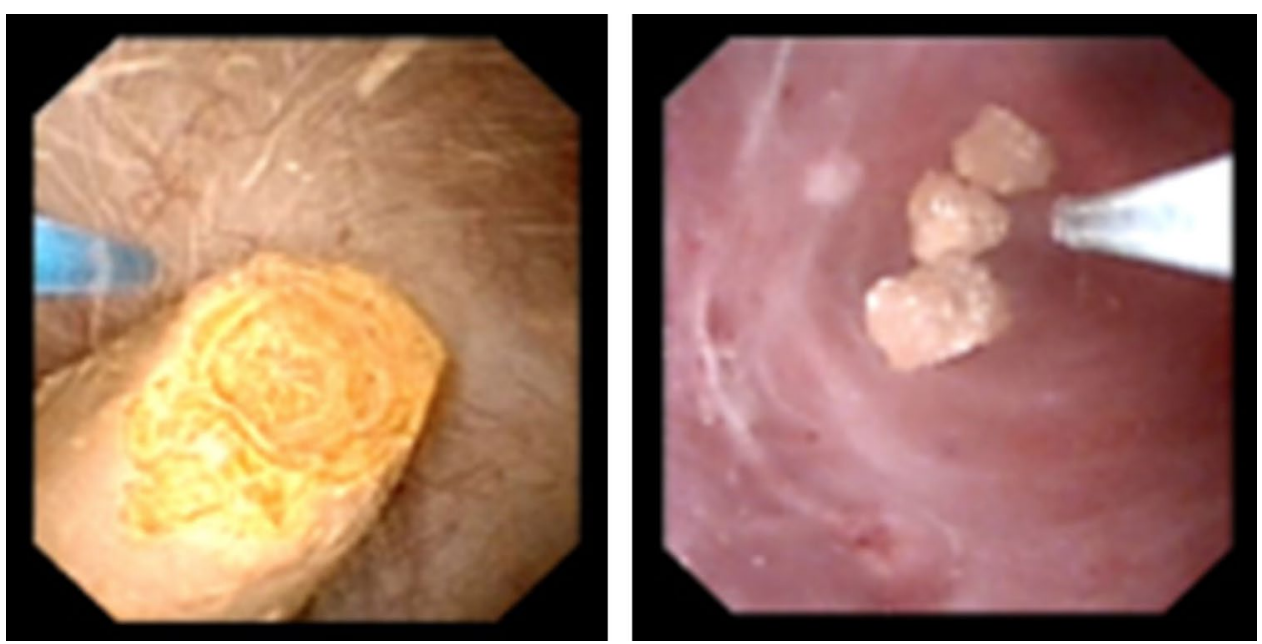
Thus, a 3 o' clock working channel position is better to ablate stones. However, to better fragment stones located in right anterior calyces, a 9 o'clock working channel position is advised. Conversely, a 9 o'clock working channel is advised for left renal stones except for posterior calyces where a 3 o'clock working channel is preferable (Fig. 6).

The last parameter to take into account is the laser fiber diameter. Large fibers $(550 \mu \mathrm{m})$ produce wider fissures, while small fibers $(200 \mu \mathrm{m})$ create deep fissures, but neither surpassed the other in terms of ablation volume [37, 38]. Although large diameter laser fibers are more resistant to fiber tip degradation or the 'burn-back' effect, their stiffness reduces fURS maximal deflection and their diameter decreases irrigation flow. Conversely, small diameter laser fibers are more fragile and prone to fiber tip degradation, but this is compensated for by better irrigation, better endoscope deflection, and less retropulsion [37, 45, 46].

Finally, when stone removal has to be performed, tipless nitinol baskets have become the standard devices and many designed are available on the market (Fig. 7). The advantages of nitinol baskets are their flexibility and ability to not damage the scope and intrarenal cavities during fragments extraction. The diameter smaller than 2.2-Fr allows maximum irrigation flow and deflection of the endoscope, whereby all parts of the collecting system can be reached [46]. Blind basketing has to be avoided as it may increase the risk for ureteral avulsion. Thus, stone retrieval with baskets, even if a UAS is used, has to be endoscopically guided. The stone and basket have to be kept under direct vision as they are removed; the size of the stone can be continually compared with the size of the ureteral lumen until the entry of the sheath if used. If the stone appears to be too large to be removed intact, it should be fragmented into smaller pieces that may be subsequently removed [47].

\section{Irrigation}

Although fURS is often performed with continuous saline irrigation through the working channel, an additional device such as syringe or manual pressure pump may be needed to improve the visibility when an instrument is inserted into the working channel, while dusting a stone or small venous bleeding happens. Furthermore, these devices may be helpful to flush stone fragments to facilitate basketing in difficult cases. However, although these irrigation pressure devices are helpful and often used, they may generate excessive intrarenal pressure, especially with an empty working channel. Depending on the irrigation system used, the level of intrarenal pressure may vary. Another factor affecting the intrarenal pressure is the physical strength of the assistant using these irrigations devices [48]. While working in the renal cavities for a long time, placing a UAS may prevent the elevation of pressure but this has to be proven (Fig. 8).
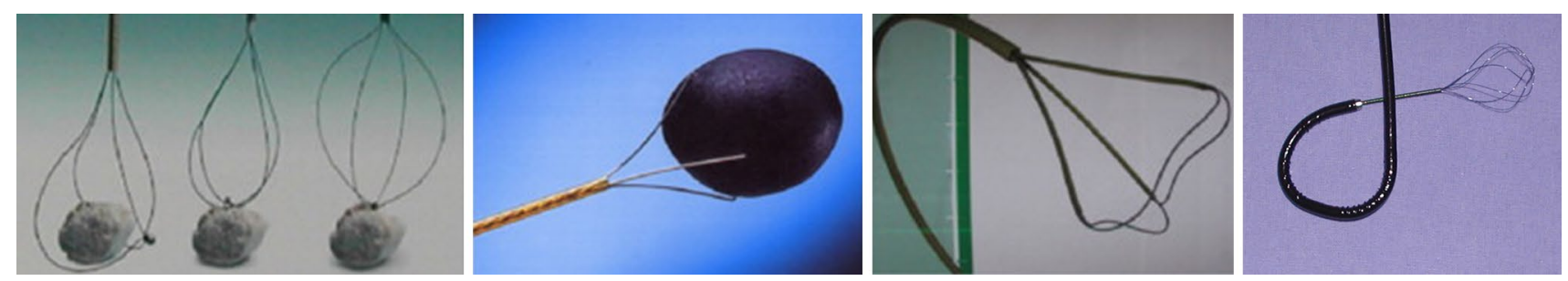

Fig. 7 Examples of nitinol baskets

Fig. 8 Hand-assisted irrigation device
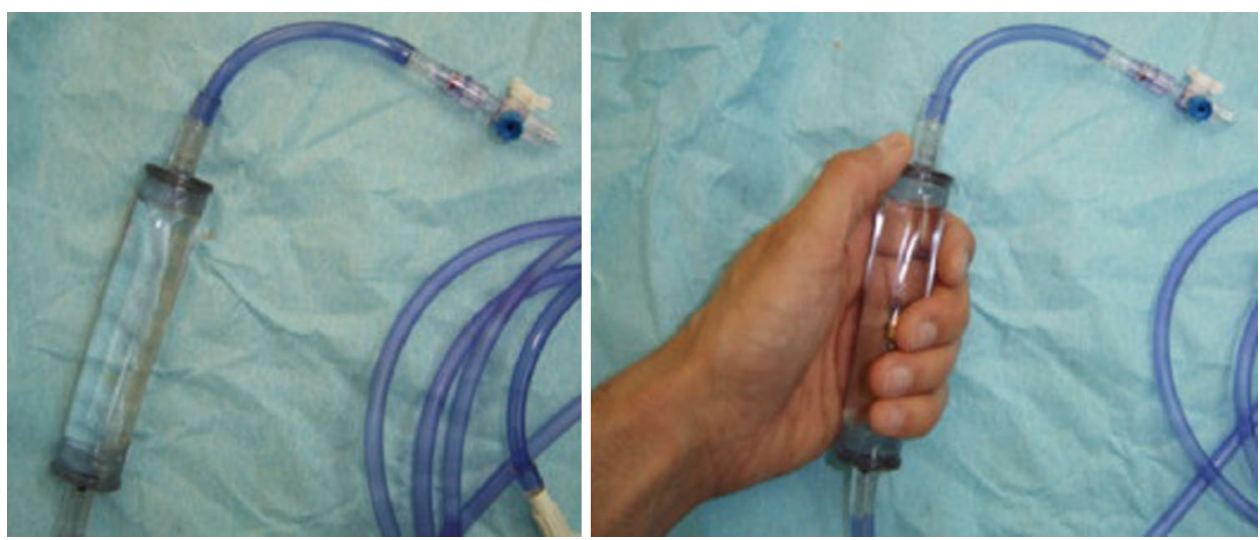


\section{Lower pole stones}

When considering lower pole stones, we have to emphasize that differences in accessing the lower pole exist between the fURSs. A recent study found that digital fURSs were less effective in accessing the sharp angled inferior calix and had lesser end-tip deflection compared with the fiberoptic fURSs. Thus, it might be better to use a fiberoptic fURS when approaching a difficult inferior calix [49].

Once fURS is in the renal cavities, attempt to relocate the stone with a nitinol basket to a more favorable position (upper pole or renal pelvis) has to be performed [50] (Fig. 9). This practice reduces the risk of fURS damage and makes the stone targeting during laser lithotripsy easier and more effective. Furthermore, according to the stone lithotripsy technique used, the stone fragments produced will be easier to grasp with the basket or able to pass spontaneously through the ureter instead of accumulating in the lower pole. However, stones larger than $10 \mathrm{~mm}$ may not be possible to grasp and relocate, necessitating laser treatment in situ, with the fURS maximally deflected, potentially increasing the risk of laser fiber failure and ureteroscope damage [51]. In that case, it is recommended to insert the laser fiber with the minimal deflection of the endoscope to avoid any working channel damage and subsequently access the lower pole to treat the stone in situ. However, once the laser fiber is in place, this results in a loss of the fURS maximal deflection and access to the lower pole may be difficult [46, 52]. For this reason has been developed a new design of laser fibers with a ball-tip shape, which reduces friction within the working channel in a completely deflected fURS, thereby reducing the likelihood of endoscope damage [53]. However, after the first minute of laser emission, the ball-shaped tip fibers lose their special feature due to fiber tip degradation, especially at high pulse energy settings [54]. Thus, this allows the insertion of a ball-tip fiber only once in a fully deflected fURS. A recent study reported that cleaving the tip of standard laser fibers with metal scissors results in equivalent passage capabilities through the deflected endoscopes than the ball-tip shaped fibers [52]. A recent work showed that laser fiber diameter and curve as well as laser settings are parameters to take into account when treating a lower pole renal stone in situ [55]. The $272 \mu \mathrm{m}$ fibers broke at the curve diameter of $9 \mathrm{~mm}$ and below for laser dusting parameters (high frequency and low energy) and $12 \mathrm{~mm}$ for the laser fragmentation parameters (low frequency and high energy). The $365 \mu \mathrm{m}$ fibers broke at $9 \mathrm{~mm}$ for the dusting parameters and required a smaller curve $(15 \mathrm{~mm})$ to break
Fig. 9 Relocation of a lower pole renal stone
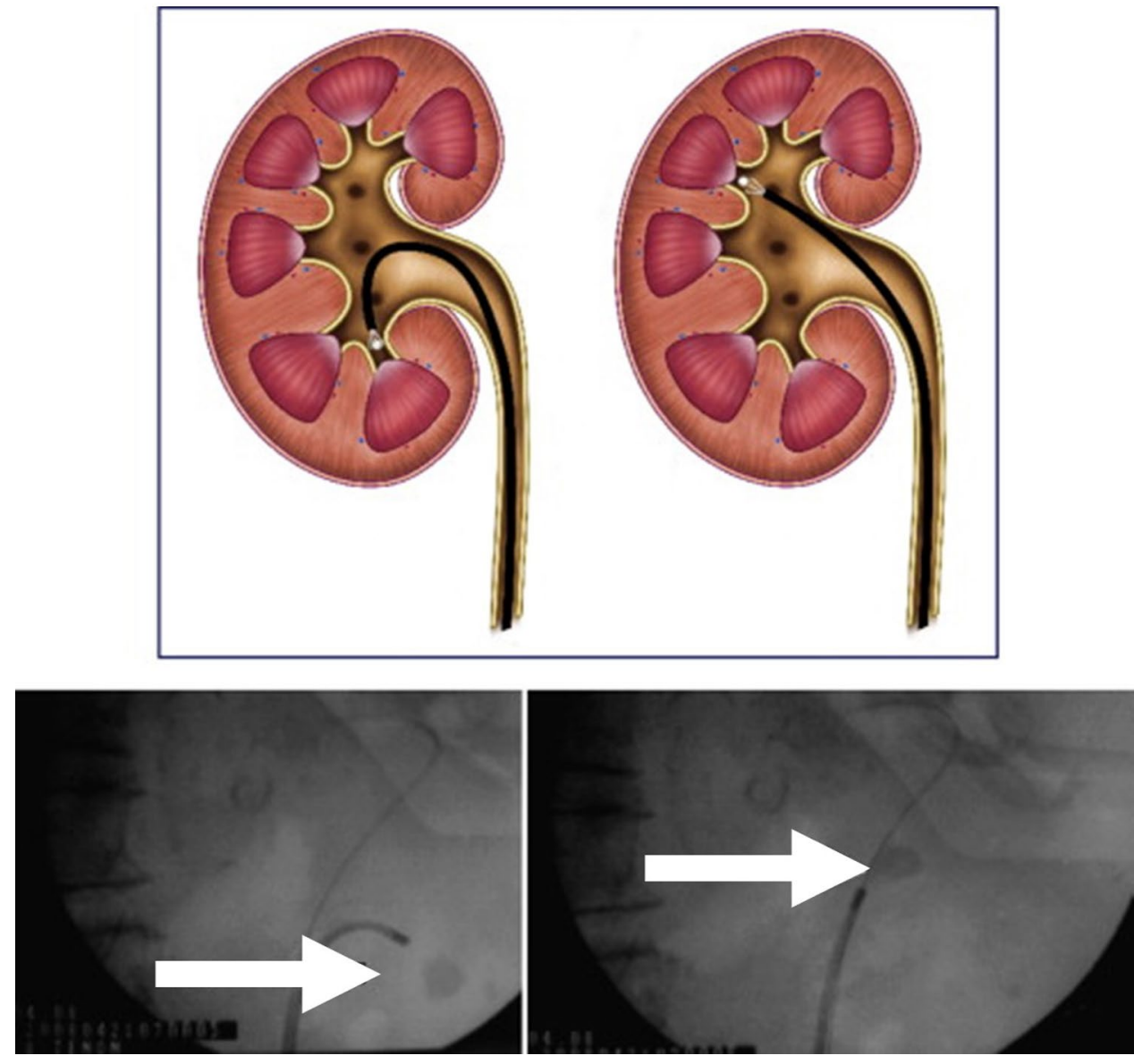
Fig. 10 a Diverticulum at the middle portion (arrow). b Flexible ureteroscope at the diverticulum. c Blue test technique
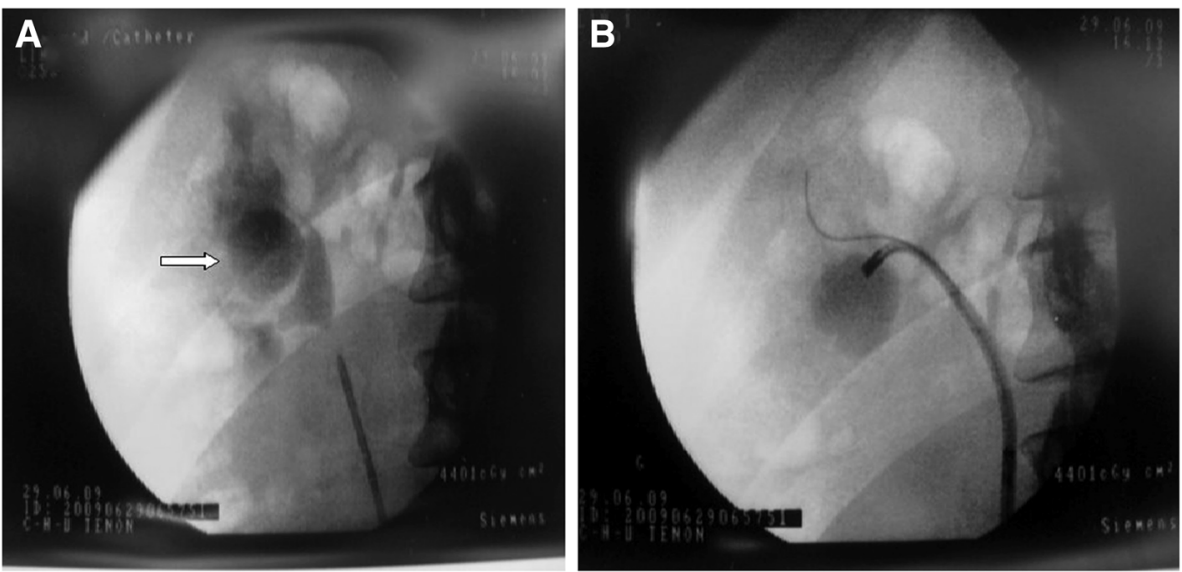

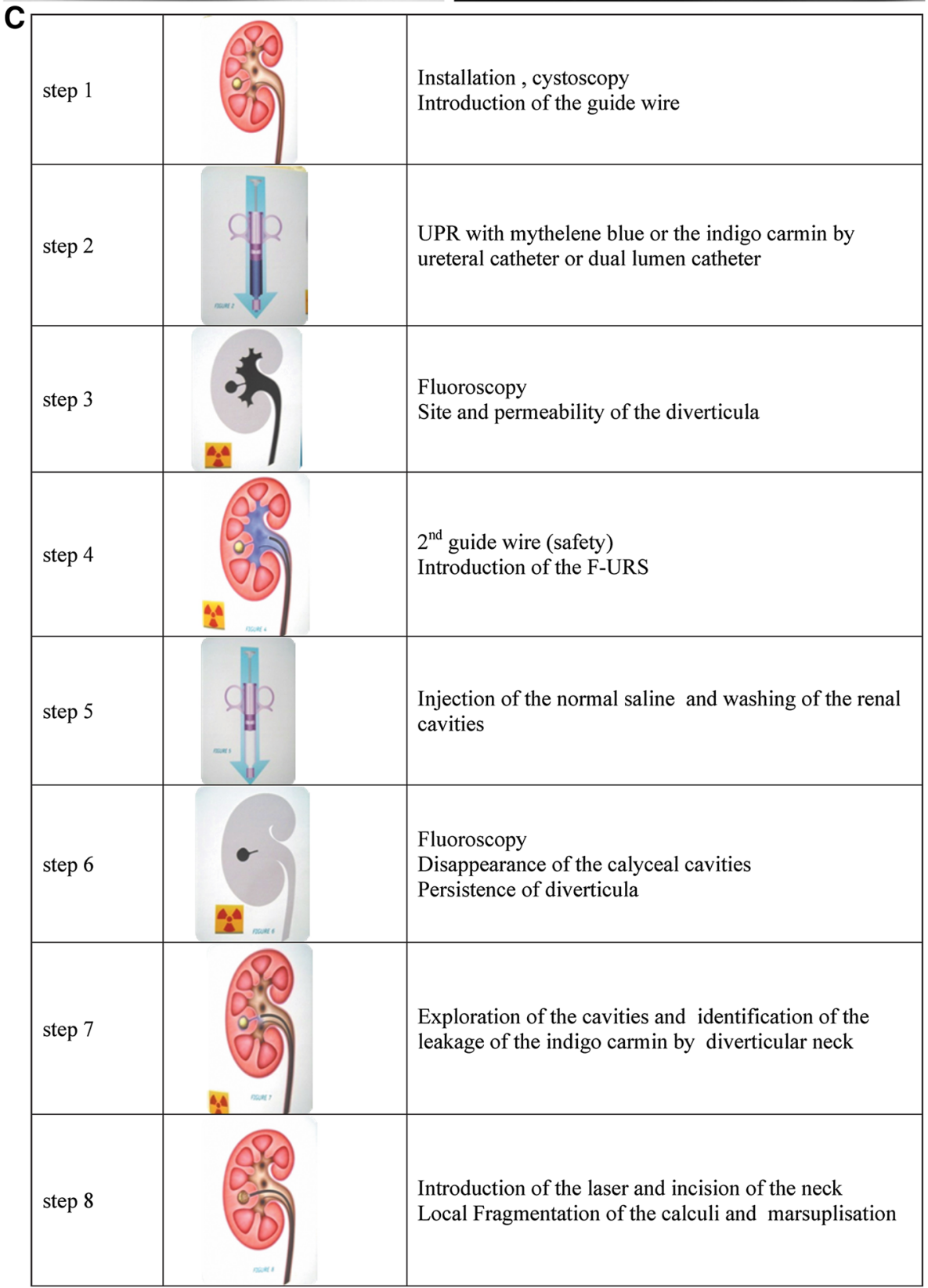


with the fragmentation parameters. Thus, to prevent laser fiber breakage, it is advised to use small $272 \mu \mathrm{m}$ fibers, at a dusting parameter, to reduce the stone diameter until it can be relocated as soon as possible.

\section{Caliceal diverticulum}

The procedure begins as standard fURS. Once the endoscope placed into the renal cavities; the principle consists of injecting contrast through the working channel to identify the diverticular neck with the assistance of fluoroscopic guidance (Fig. 10a, b). In difficult cases, it has been reported the blue test technique (Fig. 10c). Instead of injecting contrast alone, a mix of contrast and indigo carmin is injected. If opacification of the diverticulum is obtained, this means that its neck is patent. Then, the collecting system has to be washout using the saline irrigation through a manual irrigation device. Once the cavities are clear, a leakage of blue by the diverticular neck is identifiable. The next step is the laser incision of the diverticular neck and subsequently treatment of the stone burden [56].

\section{The use of apnea during laser lithotripsy}

During laser lithotripsy of renal stones or in case of precise laser ablation (upper tract urothelial carcinomas, endopyelotomy, incision of diverticular neck, stone in narrow calyx), the renal movement caused by respiration and diaphragmatic excursion makes it challenging as the surgeon has to treat a moving target without injuring urothelium or papillae. For these reasons, apnea may be needed during fURS procedure to facilitate the treatment. A recent report described a protocol to perform apnea during fURS allowing its maintenance for approximately $5 \mathrm{~min}$. This illustrates the role of the collaboration between anesthesiologists and surgeons in order to achieve the treatment [13].

\section{Ureteral stenting}

Careful ureteral exploration should be performed at the end of the procedure to retrieve the scope and the UAS while keeping the scope's tip a few centimeters out of the sheath to detect eventual ureteral lesions due to UAS placement and stone fragments [57].

To prevent the incidence of postoperative ureteric obstruction and renal colic secondary to ureteral edema, a ureteral stent may be placed. This stent placement has also been advocated to facilitate the passage of stone fragments secondary to the passive ureteric dilation [58-62]. Although this common practice is still debated, it has been reported in large series that approximately $80 \%$ of urologists place a ureteric stent after uncomplicated ureteroscopy for stone disease [63-71]. The last AUA guidelines recommend ureteral stenting among patients with ureteric injury during URS, those with evidence of ureteral stricture or other anatomical impediments to stone fragment clearance, such as ureteral wall edema, a large stone burden ( $>15 \mathrm{~mm})$, those who have an anatomically or functionally solitary kidney or renal functional impairment, and in those in whom another ipsilateral URS is planned $[9,10]$.

\section{Conclusion}

Flexible ureteroscopy has become widely used due to the technical advancements and refinements in the endourologic armamentarium made these last two decades. Its high efficacy and low morbidity in the treatment of renal stones up to $20 \mathrm{~mm}$ have made it a treatment of choice for the management of renal calculi.

\section{Compliance with ethical standards}

Conflict of interest Steeve Doizi: None. Olivier Traxer: Boston Scientific, Coloplast, EMS, Olympus, Rocamed.

\section{References}

1. Marshall VF (1964) Fiber optics in urology. J Urol 91:110-114

2. Takayasu H, Aso Y, Takagi T, Go T (1971) Clinical application of fiber-optic pyeloureteroscope. Urol Int 26(2):97-104

3. Takayasu H, Aso Y (1974) Recent development for pyeloureteroscopy: guide tube method for its introduction into the ureter. $\mathrm{J}$ Urol 112(2):176-178

4. Johnston WK 3rd, Low RK, Das S (2004) The evolution and progress of ureteroscopy. Urol Clin N Am 31(1):5-13

5. Basillote JB, Lee DI, Eichel L, Clayman RV (2004) Ureteroscopes: flexible, rigid, and semirigid. Urol Clin N Am 31(1):21-32

6. Proietti S, Dragos L, Molina W, Doizi S, Giusti G, Traxer O (2016) Comparison of new single-use digital flexible ureteroscope versus nondisposable fiber optic and digital ureteroscope in a cadaveric model. J Endourol 30(6):655-659

7. Doizi S, Kamphuis G, Giusti G, Andreassen KH, Knoll T, Osther PJ, Scoffone C, Pérez-Fentes D, Proietti S, Wiseman O, de la Rosette J, Traxer O (2017) First clinical evaluation of a new single-use flexible ureteroscope (LithoVue ${ }^{\mathrm{TM}}$ ): a European prospective multicentric feasibility study. World J Urol 35(5):809-818

8. Türk C, Neisius A, Petř́k A, Seitz C, Skolarikos A, Tepeler A, Thomas K (2017) EAU Guidelines on Urolithiasis. https://uroweb. org/guideline/urolithiasis. Accessed Oct 2017

9. Assimos D, Krambeck A, Miller NL, Monga M, Murad MH, Nelson CP, Pace KT, Pais VM Jr, Pearle MS, Preminger GM, Razvi H, Shah O, Matlaga BR (2016) Surgical management of stones: American Urological Association/Endourological Society Guideline, PART I. J Urol 196(4):1153-1160

10. Assimos D, Krambeck A, Miller NL, Monga M, Murad MH, Nelson CP, Pace KT, Pais VM Jr, Pearle MS, Preminger GM, Razvi H, Shah O, Matlaga BR (2016) Surgical management of stones: American Urological Association/Endourological Society Guideline, PART II. J Urol 196(4):1161-1169 
11. Park HK, Paick SH, Oh SJ, Kim HH (2004) Ureteroscopic lithotripsy under local anesthesia: analysis of the effectiveness and patient tolerability. Eur Urol 45(5):670-673

12. Cybulski PA, Joo H, Honey RJ (2004) Ureteroscopy: anesthetic considerations. Urol Clin N Am 31(1):43-7, viii

13. Emiliani E, Talso M, Baghdadi M, Ghanem S, Golmard J, Pinheiro H, Gkentzis A, Butticè S, Traxer O (2016) The use of apnea during ureteroscopy. Urology 97:266-268

14. Johnson GB, Portela D, Grasso M (2006) Advanced ureteroscopy: wireless and sheathless. J Endourol 20(8):552-555

15. Dickstein RJ, Kreshover JE, Babayan RK, Wang DS (2010) Is a safety wire necessary during routine flexible ureteroscopy? J Endourol 24(10):1589-1592

16. Patel SR, McLaren ID, Nakada SY (2012) The ureteroscope as a safety wire for ureteronephroscopy. J Endourol 26(4):351-354

17. Ulvik $\varnothing$, Rennesund K, Gjengst $\varnothing$ P, Wentzel-Larsen T, Ulvik NM (2013) Ureteroscopy with and without safety guide wire: should the safety wire still be mandatory? J Endourol 27(10):1197-1202

18. Dutta R, Vyas A, Landman J, Clayman RV (2016) Death of the safety guidewire. J Endourol 30(9):941-944

19. Giusti G, Proietti S, Villa L, Cloutier J, Rosso M, Gadda GM, Doizi S, Suardi N, Montorsi F, Gaboardi F, Traxer O (2016) Current standard technique for modern flexible ureteroscopy: tips and tricks. Eur Urol 70(1):188-194

20. Newman RC, Hunter PT, Hawkins IF, Finlayson B (1987) The ureteral access system: a review of the immediate results in 43 cases. J Urol 137(3):380-383

21. Rehman J, Monga M, Landman J, Lee DI, Felfela T, Conradie MC, Srinivas R, Sundaram CP, Clayman RV (2003) Characterization of intrapelvic pressure during ureteropyeloscopy with ureteral access sheaths. Urology 61(4):713-718

22. Auge BK, Pietrow PK, Lallas CD, Raj GV, Santa-Cruz RW, Preminger GM (2004) Ureteral access sheath provides protection against elevated renal pressures during routine flexible ureteroscopic stone manipulation. J Endourol 18(1):33-36

23. Kaplan AG, Lipkin ME, Scales CD Jr, Preminger GM (2016) Use of ureteral access sheaths in ureteroscopy. Nat Rev Urol 13(3): $135-140$

24. Al-Qahtani SM, Letendre J, Thomas A, Natalin R, Saussez T, Traxer O (2014) Which ureteral access sheath is compatible with your flexible ureteroscope? J Endourol 28(3):286-290

25. Emre Sener T, Cloutier J, Villa L, Marson F, Butticè S, Doizi S, Traxer O (2016) Can we provide low intrarenal pressures with good irrigation flow by decreasing the size of ureteral access sheaths? J Endourol 30(1):49-55

26. Doizi S, Knoll T, Scoffone CM, Breda A, Brehmer M, Liatsikos E, Cornu JN, Traxer O (2014) First clinical evaluation of a new innovative ureteral access sheath (Re-Trace $\left.{ }^{\mathrm{TM}}\right)$ : a European study. World J Urol 32(1):143-147

27. Breda A, Emiliani E, Millán F, Scoffone CM, Knoll T, Osther PJ, Liatsikos E (2016) The new concept of ureteral access sheath with guidewire disengagement: one wire does it all. World J Urol 34(4):603-606

28. Gupta PK (2007) Is the holmium:YAG laser the best intracorporeal lithotripter for the ureter? A 3-year retrospective study. J Endourol 21(3):305-309

29. Rassweiler J, Rassweiler MC, Klein J (2016) New technology in ureteroscopy and percutaneous nephrolithotomy. Curr Opin Urol 26(1):95-106

30. Zhong P, Tong HL, Cocks FH, Pearle MS, Preminger GM (1998) Transient cavitation and acoustic emission produced by different laser lithotripters. J Endourol 12(4):371-378

31. Rassweiler JJ, Klein J (2016) Re: update on lasers in urology. Current assessment on holmium:yttrium-aluminum-garnet (Ho:YAG) laser lithotripter settings and laser fibers. Eur Urol 70(3):538-539
32. Villa L, Cloutier J, Compérat E, Kronemberg P, Charlotte F, Berthe L, Rouchausse Y, Salonia A, Montorsi F, Traxer O (2016) Do we really need to wear proper eye protection when using holmium:YAG laser during endourologic procedures? Results from an ex vivo animal model on pig eyes. J Endourol 30(3):332-337

33. Kronenberg P, Traxer O (2015) Are we all doing it wrong? Influence of stripping and cleaving methods of laser fibers on laser lithotripsy performance. J Urol 193(3):1030-1035

34. Haddad M, Emiliani E, Rouchausse Y, Coste F, Berthe L, Doizi S, Butticè S, Somani B, Traxer O (2017) Impact of laser fiber tip cleavage on power output for ureteroscopy and stone treatment. World J Urol 35(11):1765-1770

35. Talso M, Emiliani E, Haddad M, Berthe L, Baghdadi M, Montanari E, Traxer O (2016) Laser fiber and flexible ureterorenoscopy: the safety distance concept. J Endourol 30(12):1269-1274

36. Kronenberg P, Traxer O (2015) Update on lasers in urology 2014: current assessment on holmium:yttrium-aluminum-garnet (Ho:YAG) laser lithotripter settings and laser fibers. World J Urol 33(4):463-469

37. Kronenberg P, Traxer O (2014) In vitro fragmentation efficiency of holmium:yttrium-aluminum-garnet (YAG) laser lithotripsy-a comprehensive study encompassing different frequencies, pulse energies, total power levels and laser fibre diameters. BJU Int 114(2):261-267

38. Wezel F, Häcker A, Gross AJ, Michel MS, Bach T (2010) Effect of pulse energy, frequency and length on holmium:yttrium-aluminum-garnet laser fragmentation efficiency in non-floating artificial urinary calculi. J Endourol 24(7):1135-1140

39. Spore SS, Teichman JM, Corbin NS, Champion PC, Williamson EA, Glickman RD (1999) Holmium:YAG lithotripsy: optimal power settings. J Endourol 13(8):559-566

40. Corbin NS, Teichman JM, Nguyen T, Glickman RD, Rihbany L, Pearle MS, Bishoff JT (2000) Laser lithotripsy and cyanide. J Endourol 14(2):169-173

41. Sea J, Jonat LM, Chew BH, Qiu J, Wang B, Hoopman J, Milner T, Teichman JM (2012) Optimal power settings for holmium:YAG lithotripsy. J Urol 187(3):914-919

42. Hecht SL, Wolf JS Jr (2013) Techniques for holmium laser lithotripsy of intrarenal calculi. Urology 81(2):442-445

43. Chawla SN, Chang MF, Chang A, Lenoir J, Bagley DH (2008) Effectiveness of high-frequency holmium:YAG laser stone fragmentation: the "popcorn effect". J Endourol 22(4):645-650

44. Emiliani E, Talso M, Cho SY, Baghdadi M, Mahmoud S, Pinheiro H, Traxer O (2017) Optimal settings for the noncontact holmium:YAG stone fragmentation popcorn technique. J Urol 198(3):702-706

45. Bach T, Geavlete B, Herrmann TR, Gross AJ (2008) Working tools in flexible ureterorenoscopy-influence on flow and deflection: what does matter? J Endourol 22(8):1639-1643

46. Pasqui F, Dubosq F, Tchala K, Tligui M, Gattegno B, Thibault P, Traxer O (2004) Impact on active scope deflection and irrigation flow of all endoscopic working tools during flexible ureteroscopy. Eur Urol 45(1):58-64

47. Preminger GM, Tiselius HG, Assimos DG, Alken P, Buck AC, Gallucci M, Knoll T, Lingeman JE, Nakada SY, Pearle MS, Sarica K, Türk C, Wolf JS Jr, American Urological Association Education and Research, Inc, European Association of Urology (2007) 2007 Guideline for the management of ureteral calculi. Eur Urol 52(6):1610-1631

48. Proietti S, Dragos L, Somani BK, Butticè $S$, Talso M, Emiliani E, Baghdadi M, Giusti G, Traxer O (2017) In vitro comparison of maximum pressure developed by irrigation systems in a kidney model. J Endourol 5

49. Dragos LB, Somani BK, Sener ET, Buttice S, Proietti S, Ploumidis A, Iacoboaie CT, Doizi S, Traxer O (2017) Which flexible 
ureteroscopes (digital vs. fiber-optic) can easily reach the difficult lower pole calices and have better end-tip deflection: in vitro study on K-box. A PETRA evaluation. J Endourol 31(7):630-637

50. Auge BK, Dahm P, Wu NZ, Preminger GM (2001) Ureteroscopic management of lower-pole renal calculi: technique of calculus displacement. J Endourol 15(8):835-838

51. Seto C, Ishiura Y, Egawa M, Komatsu K, Namiki M (2006) Durability of working channel in flexible ureteroscopes when inserting ureteroscopic devices. J Endourol 20(3):223-226

52. Baghdadi M, Emiliani E, Talso M, Servián P, Barreiro A, Orosa A, Proietti S, Traxer O (2017) Comparison of laser fiber passage in ureteroscopic maximum deflection and their influence on deflection and irrigation: do we really need the ball tip concept? World J Urol 35(2):313-318

53. Shin RH, Lautz JM, Cabrera FJ, Shami CJ, Goldsmith ZG, Kuntz NJ, Kaplan AG, Neisius A, Simmons WN, Preminger GM, Lipkin ME (2016) Evaluation of novel ball-tip holmium laser fiber: impact on ureteroscope performance and fragmentation efficiency. J Endourol 30(2):189-194

54. Kronenberg P, Traxer O (2016) Lithotripsy performance of specially designed laser fiber tips. J Urol 195(5):1606-1612

55. Haddad M, Emiliani E, Rouchausse Y, Coste F, Doizi S, Berthe L, Butticè S, Somani B, Traxer O (2017) Impact of the curve diameter and laser settings on laser fiber fracture. J Endourol 31(9):918-921

56. Sejiny M, Al-Qahtani S, Elhaous A, Molimard B, Traxer O (2010) Efficacy of flexible ureterorenoscopy with holmium laser in the management of stone-bearing caliceal diverticula. J Endourol 24(6):961-967

57. Traxer O, Thomas A (2013) Prospective evaluation and classification of ureteral wall injuries resulting from insertion of a ureteral access sheath during retrograde intrarenal surgery. J Urol 189(2):580-584

58. Auge BK, Preminger GM (2002) Ureteral stents and their use in endourology. Curr Opin Urol 12(3):217-222

59. Harmon WJ, Sershon PD, Blute ML, Patterson DE, Segura JW (1997) Ureteroscopy: current practice and long-term complications. J Urol 157(1):28-32
60. Netto Júnior NR, Claro Jde A, Esteves SC, Andrade EF (1997) Ureteroscopic stone removal in the distal ureter. Why change? J Urol 157(6):2081-2083

61. Knudsen BE, Beiko DT, Denstedt JD (2004) Stenting after ureteroscopy: pros and cons. Urol Clin N Am 31(1):173-180

62. Rapoport D, Perks AE, Teichman JM (2007) Ureteral access sheath use and stenting in ureteroscopy: effect on unplanned emergency room visits and cost. J Endourol 21(9):993-997

63. Nabi G, Cook J, N'Dow J, McClinton S (2007) Outcomes of stenting after uncomplicated ureteroscopy: systematic review and meta-analysis. BMJ 334(7593):572

64. Song T, Liao B, Zheng S, Wei Q (2012) Meta-analysis of postoperatively stenting or not in patients underwent ureteroscopic lithotripsy. Urol Res 40(1):67-77

65. Haleblian G, Kijvikai K, de la Rosette J, Preminger G (2008) Ureteral stenting and urinary stone management: a systematic review. J Urol 179(2):424-430

66. Tang L, Gao X, Xu B, Hou J, Zhang Z, Xu C, Wang L, Sun Y (2011) Placement of ureteral stent after uncomplicated ureteroscopy: do we really need it? Urology 78(6):1248-1256

67. Netto NR Jr, Ikonomidis J, Zillo C (2001) Routine ureteral stenting after ureteroscopy for ureteral lithiasis: is it really necessary? J Urol 166(4):1252-1254

68. Keeley FX Jr, Timoney AG (2007) Routine stenting after ureteroscopy: think again. Eur Urol 52(3):642-644

69. Gerber GS, Stockton BR (2006) Use of stents after ureteroscopic stone removal. J Endourol 20(6):383-385

70. de la Rosette J, Denstedt J, Geavlete P, Keeley F, Matsuda T, Pearle M, Preminger G, Traxer O, CROES URS Study Group (2014) The clinical research office of the endourological society ureteroscopy global study: indications, complications, and outcomes in 11,885 patients. J Endourol 28(2):131-139

71. Auge BK, Sarvis JA, L'esperance JO, Preminger GM (2007) Practice patterns of ureteral stenting after routine ureteroscopic stone surgery: a survey of practicing urologists. J Endourol 21(11):1287-1291 